\title{
Acute Uterine Inversion: Case Series from Paropakar Maternity and Women's Hospital
}

\author{
Upadhyaya I, ${ }^{1}$ Chaudhary $\mathbf{P}^{1}$ \\ ${ }^{1}$ Department of Obstetrics and Gynaecology, Paropakar Maternity and Women's Hospital Thapathali Kathmandu, Nepal.
}

\begin{abstract}
Acute puerperial uterine inversion is a rare life threatening obstetric emergency, in which the uterine fundus collapses into and out of the uterine cavity. Although precise cause is unknown, it is postulated to be caused by the mismanagement of the third stage of labour. The duration of time elapsed from moment of diagnosis to that of correction, along with rapid resuscitation measures are of utmost importance in its prognosis. Principle of treatment includes resuscitation followed by manual reduction of inversion uterus. Surgical procedure may be needed if reinversion is impossible. Reporting here are series of cases with acute inversion of uterus at third stage of labour followed by a short review of the literature.
\end{abstract}

Keywords: labour, obstetric emergency, uterine inversion.

\section{INTRODUCTION}

Inversion of the uterus is known since the time of Hippocrates. ${ }^{1}$ Acute uterine inversion is a rare and severe complication occurring in third stage of labour that is characterized by the uterine fundus protruding within the endometrial cavity, sometimes even through the cervix and into the vagina. Although uncommon, if left unrecognized, acute uterine inversion may cause severe haemorrhage and shock leading to maternal death. ${ }^{2}$ The incidence of acute puerperal inversion of the uterus varies widely. In 1940, a review showed incidence of uterine inversion to be 1 in 23127 deliveries in the USA, 1 in 27992 in the UK, and 1 in 8537 in India. ${ }^{3}$ Paropakar Maternity and Women's Hospital (PMWH) is largest maternity hospital in Nepal with more than 20,000 delivery per annum currently, where uterine inversions are often encountered.

Uterine inversion may be described as complete or incomplete depending on whether the fundus has passed through the cervix. Uterine inversion within the first 24 hours postpartum is called acute uterine inversion and is the most common type. Incomplete uterine inversion may be associated with a constriction ring and go undetected

\section{CORRESPONDENCE}

Dr Indira Upadhyaya

Department of Obstetrics and Gynaecology,

Paropakar Maternity and Women's Hospital Thapathali Kathmandu, Nepal.

Email: drindira@hotmail.com

Phone: 9851074598 for some time, resulting in subacute inversion which present after 24 hours but within four weeks of delivery or chronic inversion which presents after four weeks. ${ }^{4}$

\section{CASE 1}

A 30 years primigravida was admitted for induction of labour. Her Bishop score was four. Cervical priming was done with vaginal suppository tablet misoprostol 25 $\mu \mathrm{g}$. Vaginal delivery of alive male baby with good Apgar score occurred next day. As baby was delivered uterus was not palpable per abdomen. A big mass was noted in vagina, which revealed to be uterus with placenta, intact membrane and approximately four litres of blood. Quick resuscitation was done and uterus repositioned manually. Placenta separated spontaneously during the process of reposition and blood collected within was drained out. Bimanual massage was done and oxytocin 20 units in infusion was given. Injection methergin and injection PG F2 $\alpha$ were also given. Uterus was still not contracting and haemorrhage continued so, condom tamponade was done. Uterine contraction was maintained by oxytocin drip for 12 hours. Patient was kept under antibiotics. After 48 hours catheter deflated slowly for 10 minutes and then

The papers in this journal are published under the terms of the Creative Commons Attribution License. Users are allowed to read download, copy, distribute, print, search, or link to the full texts of the articles in this journal without asking prior permission from the publisher or the author. 
removed. Uterus was well contracted and there was no bleeding per vaginum. She received 7 units of fresh whole blood.

\section{CASE 2}

A 30 years old gravida 2 para 1 was admitted for induction of labour. She had no medical problems and had previous normal vaginal delivery. After four hours of labour, she gave birth to a healthy male baby weighing $3 \mathrm{~kg}$. Control cord traction was done before giving bolus dose of oxytocin. Then after, a mass was noticed in the introitus. There was vaginal bleeding. On examination-uterus was not palpable per abdomen. A dark reddish mass was visible outside the introitus. Patient was taken to operation theatre with diagnosis of acute inversion where uterus was manually replaced after resuscitation. Broad spectrum prophylactic antibiotic were given. Intravenous methergin $0.25 \mathrm{mg}$. was given following the repositioning of the uterus and bimanual uterine compression was maintained till strong uterine contractions were established. Thereafter, the contractions were maintained with $10 \mathrm{IU}$ oxytocin. Seven units of whole blood were transfused.

\section{CASE 3}

A 22 years old G2 P1 at 41 weeks of pregnancy was admitted with decreased fetal movement. Labour was induced after which she had vaginal delivery. She delivered alive male baby weighing $3.5 \mathrm{~kg}$. She had acute uterine inversion when cord traction was done before the action of bolus dose of intramuscular oxytocin. Resuscitation was done and she was taken to operation theatre. Reinversion was done manually under anesthesia. Three units of whole blood were transfused during the procedure.

\section{CASE 4}

A 23 years old primigravida delivered an alive female weighing $3.5 \mathrm{~kg}$. After delivery of baby, bolus oxytocin 10 IU intramuscular was administered. Uterine contraction was noted and gentle cord traction was applied in ordered to deliver the placenta. With slight cord traction, complete inversion of the uterus occurred with the placenta firmly attached to the uterine fundus. Immediately reversion of uterus was done with placenta attached by gradually rolling the lower most part of posterior edge of the uterine fundus, thereby reverting the part that inverted last. It was done under the anaesthesia. $20 \mathrm{IU}$ oxytocin in infusion was given. IM methylergometrine $0.2 \mathrm{mg}$ was also given to maintain uterine contractions. Then after, placenta was delivered by control cord traction.

\section{COMMENT}

During three years period (2006-2009), there were four cases of uterine inversion at PMWH of Kathmandu. A retrospective study in Nepal revealed six cases of puerperal inversion of the uterus. $^{5}$ Increasing number of uterine inversion may be related with the increasing number of deliveries at PMWH because of increasing institutional delivery with improving literacy rate. Incidence of uterine inversion is reported to be $1 / 20000$ in France.$^{6}$ In Europe, it is 1:20000 and 1:2000 in United States. Its incidence is 1:27802 in a British hospital. ${ }^{7}$ A retrospective study of acute puerperal inversion of the uterus undertaken at Women and Infants Hospital of Rhode Island revealed eleven inversions in 70,481 deliveries for an incidence of 1:6407. All were managed immediately which proves immediate correction of the inversion has high success rate, and loss of time may lead to surgical intervention. ${ }^{8,9}$ Not amazing, literature reports that uterine inversion can occur during caesarean section through the uterine incision while slight cord traction. As compared to vaginal delivery, incidence is much lower during caesarean section; approximately one out of $1860 .^{10-12}$

At the Ipoh General Hospital in Malaysia there were 31,394 deliveries and four acute uterine inversion occurring from 1st January 2002 to 30th June 2003. Here in PMWH from 2006 to 2008 four acute uterine inversion were studied while total number of deliveries were 56,495. This difference could be because of different management at third stage labour. The cause of acute uterine inversion is usually reported as mismanagement of the third stage of labour with premature traction on the umbilical cord and or fundal pressure before the placenta has separated. Other factors that have been implicated include manual removal of the placenta after vaginal delivary or caesarean section before complete placental separation, a sudden increase in abdominal pressure with coughing, sneezing or pushing, short cord, and morbidely adherent placenta. ${ }^{15}$ Other predisposing factors to acute uterine inversion are placenta accreta, congenital or acquired weakness of the myometrium, uterine anormalies, protracted labour, previous uterine inversion, and/or intrpartum therapy with magnesium sulfate.

In several series of cases and literature reviews no obvious cause has been found to account for $40 \%$ of cases of acute puerperal inversion ${ }^{12}$ whereas in current study showed no obvious cause in $25 \%$ cases only. Acute uterine inversion is unpredictable and the precise causes are unknown. Mismanagement of the third stage of labour has been reported to be the reason in $75 \%$ cases $^{13}$ same was true in our study. Excessive cord traction in the absence of placental separation is the possible factor to induce uterine inversion. A study showed $60 \%$ of all cased of uterine inversion are cause by traction or improper fundal pressure. ${ }^{16}$ Current study showed $75 \%$ cases were related 
to improper cord traction.

A study done at the university hospital, Kuala Lumpur over period of 17 years, reported 15 patients with acute puerperial inversion of the uterus who were managed by combinations of both technique: manual replacement and hydrostatic method and most cause of inversion was injudicious traction on the umbilical cord before the uterus was well contracted. ${ }^{14}$

The diagnosis of uterine inversion is clinical, based on three elements strong pain abdomen, haemorrhage, and shock. The hemorrhage is directly associated to the inversion duration. In our case series, $75 \%$ women had massive haemorrhage. Shock can be neurogenic (13\%) in origin too, owing parasympathetic effect of traction on infundibulopelvic ligaments or secondary to peritoneal or broad ligament stretching. ${ }^{10}$ The sudden severe pain is less frequent and is present in 7 to $10 \%$ of cases. ${ }^{7}$ In current study three out of four cases had blood transfusion upto seven units due to PPH. In a study of eleven inversions, six patients had blood loss greater than $1000 \mathrm{ml}$ and three patients required blood transfusion. In this study one patient even needed intrauterine condom catheter tamponade to control the PPH due to atony of the uterus.

The management of acute uterine inversion is urgent which begins with the establishment of an intravenous line if not previously made and the initiation of fluid therapy to resuscitate the mother and immediate reversion of the uterus. This should be done without prior placental separation. The technique involves placing the whole of the hand to be used in the reduction into the vagina and applying pressure with the tips of the fingers to the junction of the cervix and the corpus. Pressure should also be applied to the inverted fundus which is held in the cupped palm of the hand, to ensure that portion of the uterus which inverted last to be replaced first, for which uterine relaxation is necessary. Literature recommends using the neuromuscular relaxant molecules such as the magnesium sulphate, betamimetic, nitrate based products etcx. ${ }^{7}$ In our study, in all four cases uterine reinversion was done at operation theatre under anesthesia, manually after correction of shock. Failing manual reduction, the hydrostatic method described by O'Sullivan should be attempted. If this method also fails, operative intervention is necessary, vaginal or abdominal approach. Spinelli describes vaginal route correction of inverted uterus followed by repair of the incision with upward anterior division of the cervical constriction ring as well as the lower part of the inverted uterus. Abdominal approaches include direct traction on the inverted fundus using an Allis forceps stepwise traction on both round ligaments using Spencer-Wells forceps. If this fails, Haltain advised incising the posterior cervical ring to permit reduction and subsequent repair of the uterus. Once the uterus is reduced by whatever means, intravenous oxytocics should be used to keep the uterus contracted and the patient should be started on prophylactic antibiotic therapy. ${ }^{17-19}$ Final resolution, hysterectomy is indicated for a gangrenous or haemorrhagic uterus despite the reduction and medical treatment.

Acute uterine inversion can reoccur but still uncomplicated births are anticipated in subsequent pregnancies. Patient should be well counseled for family planning as well as the need for the professionally supervised birth if decide to conceive in future. ${ }^{20,21}$

Acute uterine inversion during vaginal birth is a serious and often unexpected obstetric complication, which occurs due to mismanagement of third stage of labour. An obstetrician should be aware of this complication. Prompt diagnosis and uterine reversion without any delay are the key to success in the management of this life threatening obstetric emergency failing which maternal morbidity and even mortality is inevitable.

\section{REFERENCES}

1. Gowri V. Uterine inversion and corpus malignancies: a historical review. Obstet Gynecol Surv. 2000;55:703-7.

2. Hostetler DR, Bosworth MF. Uterine inversion: a lifethreatening obstetric emergency. J Am Board Fam Pract. 2000;13(2):120-3.

3. Anthony J, Goldberg GS, Zabow PC. Acute puerperal uterine inversion. A Afr Med J. 1984;66:738-9.

4. Thompson W, Harper A. Postpartum hemorrhage and abnormalities of the third stage of labour. In: Chamberlain G, Steer PJ, editors. Turnbull's Obstetrics. 3rd ed. London: Churchill Livingstone;2001;619-33.

5. Dali SM, Rajbhandari S, Shrestha S. Puerperal inversion of the uterus in Nepal: case reports and review of literature. J Obstet Gynaecol Res. 1997;23(3):319-25.

6. Find health articles.com. Acute puerperal uterine inversion: two cases. Research article summary (published 30 Oct 2002).

7. Bouchikhi C, Saadi H, Fakhir B, Chaara H, Bouguern H. Uterine inversion: a case report. J Med Liban. 2009;16:1-3.

8. Shah-Hosseini R, Evrard JR. Puerperal uterine inversion. Obstet Gynecol. 1989;73(4):567-70.

9. Awad JT, Azar GB, Karam KS. Puerperal uterine inversion. J Med Liban. 1992;40(3):169-72.

10. Vavilis D, Tsolakidis D, Athanatos D, Goutzioulis A, Bontis NJ. Complete uterine inversion during caesarean section: a case report. Cases Journal. 2008;127:1-5.

11. Baskett TF. Acute uterine inversion: a review of 40 cases. J Obstet Gynaecol Can. 2002; 24(12):953-6. 
12. Cumming DC, Taylor PJ. Puerperal uterine inversion: report of nine cases. Can Med Assoc J. 1978;118(10):1268-70.

13. Dim CC. Acute uterine inversion in rural African women: rare consequences of child birth. Women and Birth. 2009;22:257.

14. Rachagan SP, Sivanesaratnam V, Kok KP, Raman S. Acute puerperal inversion of the uterus-an obstetric emergency. Aust N Z J Obstet Gynaecol. 1988;28(1):29-32.

15. Achanna S, Mohamed Z, Krishan M. Puerperal uterine inversion: a report of four cases. J Obstet Gynaecol Res. 2006;32(3):341-5.

16. Sequeira E, Patel Y. Acute puerperal uterine inversion: case report. East Afr Med J. 2007;84(4):194-6.

17. Studzinski Z, Branicka D. Acute complete uterine inversion case report. Ginekol Pol. 2001;72(11):881-4.
18. Lago JD. Presentation of acute uterine inversion in the emergency department. Am J Emerg Med. 1991;9(3):23942.

19. Brar HS, Greenspoon JS, Platt LD, Paul RH. Acute puerperal uterine inversion. New approaches to management. J Reprod Med. 1989;34(2):173-7.

20. Rana A, Pradhan N, Giri K, Bista D, Thakur JK. Acute uterine inversion reverted by laparotomy and division of ring anteriorly: Dobbins operation. Singapore J Obstet Gynaecol. 2002;33(3):50-4.

21. Chaudhary R, Gurung G, Amatya A, Saki K, Maharjan S. An inverted uterine fundus carrying placenta: how does this happen or why is it mistaken? N J Obstet Gynaecol. 2007;2(2):69-71. 